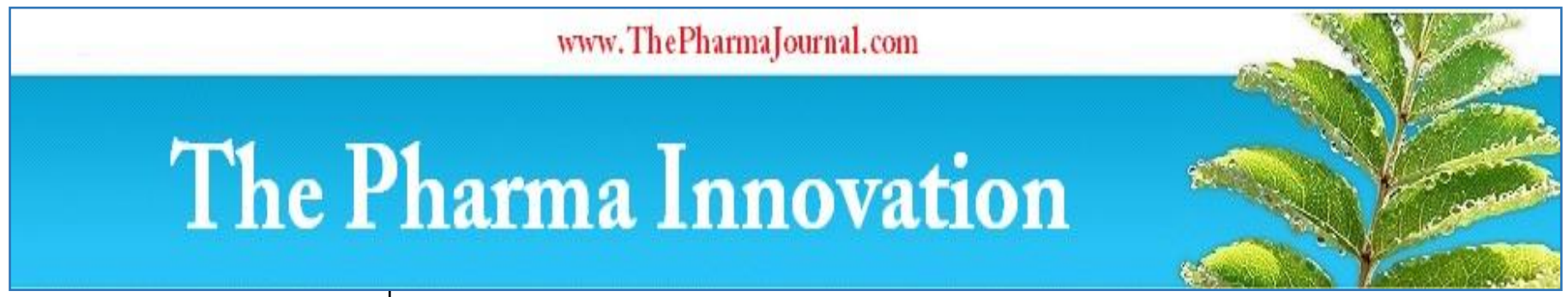

ISSN (E): 2277 - 7695

ISSN (P): 2349-8242

NAAS Rating: $\mathbf{5 . 0 3}$

TPI 2020; 9(7): 186-190

(C) $2020 \mathrm{TPI}$

www.thepharmajournal.com

Received: 12-05-2020

Accepted: 14-06-2020

\section{Mandakini Kabi}

Ph.D., Scholar, Department of Plant Breeding and Genetics,

College of Agriculture, OUAT, Bhubaneswar, Odisha, India

Bhabendra Baisakh

Professor (PB\&G), Department of Plant Breeding and Genetics, College of Agriculture, OUAT,

Bhubaneswar, Odisha, India

\section{Manasi Dash}

Assoc. Professor, (PB\&G),

Department of Plant Breeding and Genetics, College of

Agriculture, OUAT,

Bhubaneswar, Odisha, India

\section{Swapan K Tripathy}

Professor, Department of

Agricultural Biotechnology,

College of Agriculture, OUAT,

Bhubaneswar, Odisha, India

Corresponding Author: Swapan K Tripathy

Professor, Department of Agricultural Biotechnology, College of Agriculture, OUAT, Bhubaneswar, Odisha, India

\section{Study of genetic diversity based on quantitative traits in sesame}

\author{
Mandakini Kabi, Bhabendra Baisakh, Manasi Dash and Swapan K Tripathy
}

DOI: https://doi.org/10.22271/tpi.2020.v9.i7c.4856

\begin{abstract}
In the present investigation thirty sesame genotypes were used for diversity analysis for thirteen quantitative traits. The thirty genotypes were grouped into nine clusters based on the Mahalanobis $\mathrm{D}^{2}$ values following Tocher's method. There was similarity of clustering pattern obtained by both Tocher's method and canonical analysis. Maximum inter cluster distance (1840.33) was exhibited between cluster IV and cluster VI and intra cluster distance (154. 89) was in cluster III. The lowest inter cluster divergence (165.90) was noticed between cluster II and VI indicating that the genotypes included in them were closely related. So, it is expected that crosses between genotypes of cluster IV with genotypes of cluster VI will give rise to high yielding sergeants. Relative contribution of different characters to total divergence was assessed through comparison of actual $\mathrm{D}^{2}$ values for individual characters over all possible combinations. It was revealed that capsule per plant followed by days to $50 \%$ flowering and 100 seed weight contributed maximum to total divergence.
\end{abstract}

Keywords: Genetic diversity, $\mathrm{D}^{2}$ analysis, canonical analysis, clustering pattern, sesame

\section{Introduction}

Sesame is considered as queen of oilseed crops because of its high nutritional value and health benefits. Its oil is highly resistant to oxidative deterioration as compared to other edible oils due to the presence of lignans mainly sesamin, sesamolin, sesamol and $\gamma$-tocopherol (Fukuda et al. 1986) [8]. Besides, sesame oil has cosmetic and pharmaceutical value as it contains bioactive compounds e.g., phenolics, phytosterols, phytates and short chain peptides (Pornparn et al. 2009) ${ }^{[15]}$. However, its cultivation is not widespread in India owing to its poor national productivity $(431 \mathrm{~kg} / \mathrm{ha})$ compared to world average $(512 \mathrm{~kg} / \mathrm{ha})\left(\right.$ FAO Statistics, 2020) ${ }^{[7]}$. Most of the varieties in cultivation are selections from locals or closely related populations grown under low levels of management which in turn give low productivity. In this context, replacement of traditional old varieties by high yielding hybrid and/or improved varieties tolerant to biotic and abiotic stresses can be an appropriate and viable alternative (Lakhanpaul et al. 2012) ${ }^{[11]}$.

Development of variety depends upon the selection of divergent genetic resources as parents in crop improvement programme. Therefore, assessment of genetic distance among genotypes is of immense value for creation of variability. Mahalanobis D ${ }^{2}$ statistic (Mahalanobis 1936) ${ }^{\text {[12] }}$ is a powerful tool for estimation of genetic divergence in a given population. Divergent genotypes could be obtained by collection from different eco- geographical regions or it could be induced by combination breeding. It is generally suggested that genetic diversity must form the sound base for selecting parental genotypes for hybridization leading to development of high yielding varieties rather than to create geographical diversity (Anuradha and Reddy, 2008) ${ }^{[4]}$. However, reports on study of genetic diversity in sesame are quite limited. Experimental results what-so-ever available cannot be generalized, but are relevant to the set of materials and the specific environment under which those are tested. Therefore, an attempt was undertaken to study genetic divergence of a set of available core germplasm lines under the environment where it is to be exploited for genetic improvement using recombination breeding.

\section{Material and methods}

The experimental materials for present study comprised of 30 genotypes collected from diverse sources (Table 1). These were grown during kharif, 2016-17 in RBD design with three replications at EB-II section of the Department of Plant Breeding and Genetics, OUAT, Bhubaneswar. Geographically, the experimental site is located at $20^{\circ} 52^{\prime} \mathrm{N}$ latitude, $82^{\circ} 52^{\prime} \mathrm{E}$ 
longitude and at an altitude of $25.9 \mathrm{~m}$ above the mean sea level and nearly $64 \mathrm{~km}$ west of the Bay of Bengal which comes under the humid and subtropical climate zone of the state. Each entry was sown in 5 rows of 3-meter length with a spacing of $30 \mathrm{~cm}$ x $10 \mathrm{~cm}$. Recommended dose of fertilizers and need based plant protection measures were followed to raise a good crop. To minimize any border effect, one extra row on either side of each plot was sown. Observations were recorded for thirteen characters namely days to $50 \%$ flowering, days to maturity, plant height, plant height up to first branching, plant height up to first capsule bearing node, branches per plant, internode length, capsules per plant, seeds per capsule, capsule length, capsule width, 100-seed weight and yield per plant. Out of the 13 quantitative traits, days to $50 \%$ flowering and days to maturity were recorded on the plot basis, while rest of the traits were assessed based on 5 randomly selected competitive plants per plot in each replication.

Analysis for diversity study was done by Mahalanobis $\mathrm{D}^{2}$ statistic and canonical analysis following Rao (1952) ${ }^{[16]}$. A simultaneous test of significance difference in mean values of twelve correlated variables of 30 genotypes was carried out using Wilk's Lambda $(\lambda)$ criterion and V-statistics (Rao, 1952) ${ }^{[16]}$. The genotypes were grouped into clusters on the basis of $\mathrm{D}^{2}$ values following Tocher's method. Canonical analysis was done following Anderson (1958) ${ }^{[3]}$ and the $Z_{1}$ and $Z_{2}$ values corresponding to the first two canonical vectors plotted as a supplement to grouping by Tocher's method. Grouping of the population was inferred from their relative dispersion in the $\mathrm{Z}_{1}-\mathrm{Z}_{2}$ graph.

Table 1: List of 30 sesame test genotypes studied for genetic divergence

\begin{tabular}{|c|c|c|c|c|c|}
\hline S. No. & Genotype & Source & Sl. & Genotype & Source \\
\hline 1 & AT-345 & ARS, JAU, Amreli (Gujrat) & 16 & TKG-308 & ZARS, Tikamgarh (MP) \\
\hline 2 & AT-382 & - do- & 17 & RT-54 & ARS, RAU, Mandore (Rajasthan) \\
\hline 3 & AT-393 & - do- & 18 & RT-125 & ARS, RAU, Mandor (Rajasthan) \\
\hline 4 & AT-394 & - do- & 20 & RT-351 & ARS, RAU, Mandore (Rajasthan) \\
\hline 5 & AT-400 & - do- & 21 & Amrit & AICRP- Sesame, (OUAT, Odisha) \\
\hline 6 & AT-403 & -do- & 22 & Krishna & RAU, Dholi (Bihar) \\
\hline 7 & AT-404 & - do- & 23 & Kanak & OUAT, Bhubaneswar (Odisha) \\
\hline 8 & BS-129 & -do- & 24 & Nirmala & OUAT, Bhubaneswar (Odisha) \\
\hline 9 & CO-1 & TNAU, Coimbatore (TN) & 25 & Prachi & OUAT, Bhubaneswar (Odisha) \\
\hline 10 & GT-10 & RAS, GAU, Amreli (Gujrat) & 26 & Rama & PORS, Berhampore (WB) \\
\hline 11 & JT-7 & ZARS, Powarkheda (MP) & 27 & Smarak & AICRP -Sesame, (OUAT, Odisha) \\
\hline 12 & JT-12 & -do- & 28 & Sekhar & CSAU, Kanpur (U.P.) \\
\hline 13 & JT-14 & -do- & 29 & Savitri & PORS, Berhampore (WB) \\
\hline 14 & VRI-1 & TNAU, Coimbatore (TN) & 30 & Uma & OUAT, Bhubaneswar (Odisha) \\
\hline 15 & OSM-22 & - & &
\end{tabular}

\section{Result and discussion}

The success from hybridization programme is expected from the combination of genetically diverse parents which have role in the heterotic expression and segregation potential of crosses (Tripathy et al. 2016) ${ }^{[19]}$. For this purpose, all the thirty genotypes were grouped into nine clusters following Tocher's method (Table 2, Fig 1) on the basis of genetic diversity as measured by Mahalanobis $\mathrm{D}^{2}$-values. Out of these, cluster I was the largest cluster comprising of eight genotypes followed by cluster $\mathrm{V}$ consisting of six genotypes, cluster III including five genotypes, cluster VII consisting four genotypes and cluster II three genotypes. Rest four clusters were monogenotypic suggesting the existence of high degree of heterogeneity among the genotypes. There was close similarity of clustering pattern obtained by both Torcher's method and canonical analysis. This supports the findings of Parameswarappa et al. (2010) ${ }^{[14]}$ and Ahadu (2012) ${ }^{[2]}$ though the number of clusters differed depending on the number of genotypes and characters studied.

Inter and intra cluster $\mathrm{D}^{2}$ values were worked out from divergence analysis. Critical assessment of clusters showed that clusters were heterogeneous within themselves and between each other based on major character. The intra cluster distance ranged from 0.00 to 154.89 and the inter cluster distance ranged from 165.90 to 1840.33 , indicating that the selected genotypes were highly divergent (Fig 2). Maximum inter cluster distance (1840.33) was exhibited between cluster IV and cluster VI. Greater the distance between two clusters, wider the genetic diversity among the genotypes. The lowest inter cluster divergence (165.90) was noticed between cluster II and VI indicating that the genotypes included in them were closely related. It indicated that these accessions were closely related in their evolutionary process which passed through similar evolutionary factor. Avoidance of selection of parents from genetically homogeneous clusters should be preferred to maintain relatively broad genetic base. So, it is expected that crosses between genotypes of cluster IV with genotypes of cluster VI will give rise to high yielding segregants because of highest inter-cluster distance (1840.33). Similar results were obtained by Tripathi et al. (2013) ${ }^{[18]}$, Hika et al. (2015) ${ }^{[9]}$ and Dash et al. (2018) ${ }^{[6]}$. Such grouping of genotypes from different genetic origin may be attributed to the unidirectional selection practiced by the breeder in a particular location (Singh and Bains, 1968) ${ }^{[17]}$. However, Murty and Arunachalam (1966) ${ }^{[13]}$ have reported that genetic drift and selection, both natural and artificial in different environments could cause greater diversity among genotypes than geographic distances. Probably due to above two factors, the genotypes originating from the different crosses have been clustered together.

Relative contribution of different characters to total divergence was assessed through comparison of actual $\mathrm{D}^{2}$ values for individual characters over all possible combinations. It was revealed that capsule per plant (19.37) followed by days to $50 \%$ flowering (16.53) and 100 seed weight (12.46) contributed maximum to total divergence (Table 3). The characters contributing maximum to divergence needs greater emphasis for deciding on the clusters for the purpose of selection of parents in the respective cluster for hybridization. Out of thirteen characters studied, five characters namely capsule per plant (19.37) followed by days to $50 \%$ flowering (16.53), 100 seed weight (12.46), branches per plant (10.90) and day to maturity (7.94) contributed $67.20 \%$ towards total divergence. Therefore, these 
characters should be given importance during selection of parents for hybridization and also in the follow-up selection of segregating populations. Similar observation was reported by Chandramohan (2011) ${ }^{[5]}$, Abate and Mekbib (2015) ${ }^{[1]}$ and Kiranmayi et al. (2016) ${ }^{[10]}$. Thus, contribution of characters to divergence depends on the number of characters studied and the influence of the environment on the expression of characters.

The cluster mean values were estimated over genotypes for thirteen agro-morphological traits including seed yield in sesame, which revealed that a wide range of variation (Table 4) existed among clusters. It can be seen from the data that considerable differences existed for all the characters under study. Cluster IV revealed longer maturity duration(90days), highest plant height $(130.7 \mathrm{~cm})$ with maximum capsules/plant (122.0) and also seeds/ capsule (67.4) resulting highest seed yield/plant (15.2g), while Cluster VI recorded comparatively larger seeds with maximum 100 -seed weight of $0.41 \mathrm{~g}$. In contrast, genotypes in Cluster II and Cluster VI exhibited early flowering ( 26 days) and marurity duration( $\sim 80$ 82 days). The results indicate that selection of genotypes with high cluster mean values for particular attribute could be used in the hybridization programme for improvement of that character. A key assessment of the observation indicates that none of the clusters contained genotypes with all the desirable traits which could be directly selected and utilized for general cultivation. Therefore, depending upon the objective of the breeding programme to derive superior transgressive segregants for desired character, hybridization between the selected genotypes from divergent clusters is essential to judiciously combine all the targeted traits.

Table 2: Clustering of 30 sesame genotypes using Tocher's method

\begin{tabular}{|c|c|c|}
\hline Cluster & No. of genotypes & Name of genotypes \\
\hline I & 8 & AT-345, Sekhar, Amrit, AT-404, Smarak, VRI-1.AT-392, TKG-308 \\
\hline II & 3 & AT-382, JT-14, JT-7 \\
\hline III & 5 & AT-393, RT-127, AT-400, RT-125, Nirmala \\
\hline IV & 1 & Rama \\
\hline V & 6 & CO-1, BS-129, Kanak, GT-10, Savitri, AT-403 \\
\hline VI & 1 & JT-12 \\
\hline VII & 4 & OSM-22, Krishna, RT-351, RT-54 \\
\hline VIII & 1 & Prachi \\
\hline IX & 1 & Uma \\
\hline
\end{tabular}

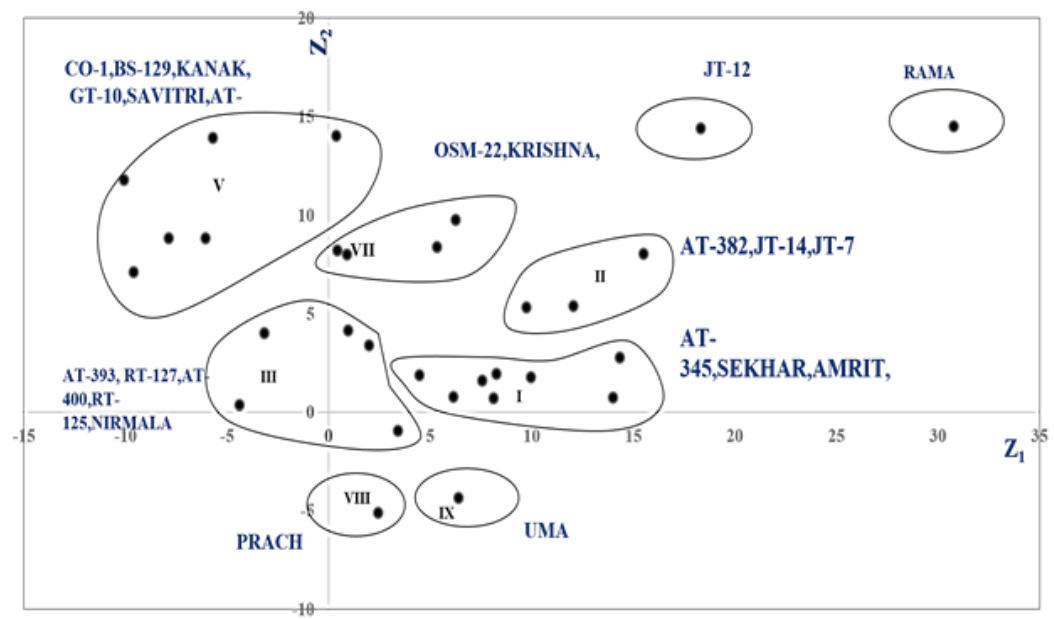

Fig 1: Grouping of 30 sesame genotypes based on canonical values.

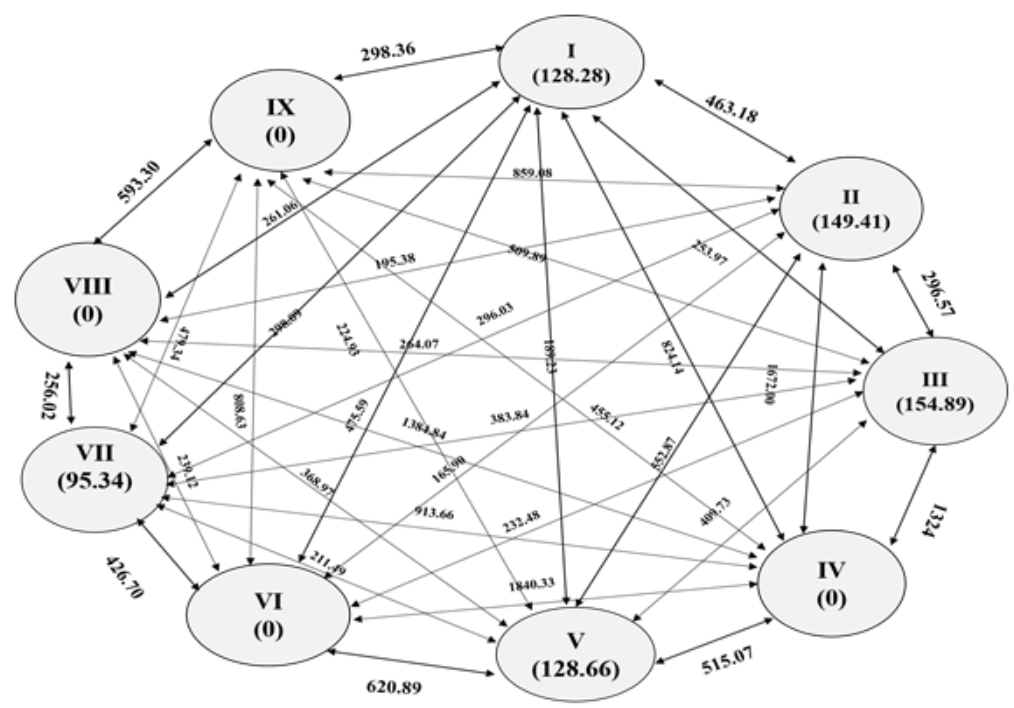

Fig 2: Graphical representation of inter and intra-cluster distance ( $\mathrm{D}^{2}$-values) among nine clusters in sesame (distance not to the scale). 
Table 3: Relative contribution of 13 agro-morphological traits to total genetic divergence.

\begin{tabular}{|c|c|c|c|c|}
\hline Characters & Average $\mathbf{D}^{\mathbf{2}}$ value & \% of $\mathbf{D}^{\mathbf{2}}$ Value & Rank Total & \% of Rank Total \\
\hline DF & 49.19 & 16.53 & 2039 & 5.39 \\
\hline DM & 23.63 & 7.94 & 2646 & 6.99 \\
\hline PH & 9.32 & 3.13 & 3641 & 9.62 \\
\hline PHB & 10.49 & 3.52 & 3374 & 9.91 \\
\hline PHC & 4.27 & 1.43 & 3696 & 6.20 \\
\hline B/P & 32.44 & 10.90 & 2347 & 7.07 \\
\hline IL & 20.24 & 6.80 & 2677 & 5.37 \\
\hline S/P & 57.63 & 19.37 & 2034 & 8.53 \\
\hline CL & 11.32 & 3.80 & 3230 & 8.36 \\
\hline CW & 16.30 & 5.48 & 3654 & 9.65 \\
\hline SO-SW & 8.34 & 2.80 & 2341 & 6.18 \\
\hline SY/P & 37.08 & 12.46 & 2994 & 7.91 \\
\hline Total & 17.33 & 5.82 & 37.84 & 100 \\
\hline
\end{tabular}

N.B.: DF- days to $50 \%$ flowering, DM-days to maturity, PH- plant height $(\mathrm{cm})$, PHB- plant height up to $1^{\text {st }}$ branching $(\mathrm{cm})$, PHC- plant height $1^{\text {st }}$ capsule bearing node $(\mathrm{cm})$, B/P-no. of branches/plant, IL- internode length $(\mathrm{cm}), \mathrm{C} / \mathrm{P}-$ no. of capsules/plant, S/C-no. of seeds/capsule, CL-capsule length $(\mathrm{cm})$, CW-capsule width $(\mathrm{cm}), 100 \mathrm{SW}-100$ seed weight $(\mathrm{g})$ and SY/P- seed yield/plant $(\mathrm{g})$.

Table 4: Cluster means of 13 agro-morphological traits in a set of 30 sesame germplasm lines.

\begin{tabular}{|c|c|c|c|c|c|c|c|c|c|}
\hline \multirow{2}{*}{ Characters } & \multicolumn{9}{|c|}{ Clusters } \\
\cline { 2 - 10 } & I & II & III & IV & V & VI & VII & VIII & IX \\
\hline DF & 33.5 & 25.3 & 29.4 & 40.0 & 32.1 & 26.0 & 31.9 & 28.0 & 38.0 \\
\hline DM & 85.6 & 79.7 & 82.6 & 90.0 & 84.5 & 82.0 & 84.8 & 80.0 & 93.0 \\
\hline PH & 93.8 & 86.6 & 90.2 & 130.7 & 100.3 & 80.2 & 100.3 & 74.1 & 88.3 \\
\hline PHB & 15.2 & 12.1 & 13.7 & 26.7 & 16.9 & 12.4 & 17.4 & 13.1 & 13.3 \\
\hline PHC & 27.7 & 25.2 & 26.4 & 45.3 & 31.2 & 30.4 & 33.3 & 21.6 & 23.6 \\
\hline B/P & 2.17 & 1.77 & 1.97 & 4.20 & 2.53 & 1.37 & 2.52 & 1.73 & 4.50 \\
\hline IL & 6.25 & 6.81 & 6.53 & 5.13 & 6.18 & 5.00 & 5.71 & 4.80 & 3.60 \\
\hline C/P & 44.0 & 27.9 & 35.9 & 122.0 & 57.4 & 25.3 & 60.1 & 34.2 & 53.1 \\
\hline S/C & 63.1 & 58.2 & 60.7 & 67.4 & 62.3 & 64.1 & 63.6 & 60.0 & 66.2 \\
\hline CL & 2.67 & 2.19 & 2.43 & 2.30 & 2.40 & 1.80 & 2.23 & 2.60 & 2.50 \\
\hline CW & 0.61 & 0.67 & 0.64 & 0.56 & 0.62 & 0.72 & 0.64 & 0.75 & 0.69 \\
\hline 100-SW & 0.39 & 0.34 & 0.36 & 0.28 & 0.34 & 0.41 & 0.35 & 0.33 & 0.34 \\
\hline SY/P & 7.29 & 5.42 & 6.36 & 15.2 & 8.57 & 4.18 & 8.58 & 4.48 & 8.49 \\
\hline
\end{tabular}

\section{Conclusion}

The present study provides information for most of the characters and their possible use in hybridization programme. Crosses can be made between genotypes of cluster IV with genotypes of cluster VI to isolate desirable high yielding segregants. However, crossing between most divergent genotypes may not yield proportionate heterotic response because a cross between extremely divergent parents may create a situation where the harmonious functioning of alleles is somewhat disturbed and consequently the physical functions are not that much efficient as in a situation where the alleles are exposed to similar selection pressure. Although many workers have suggested the use of $\mathrm{D}^{2}$-analysis in choosing parents for hybridization, the reports on comparative empirical verification as done in the present study is rather limited.

\section{References}

1. Abate M, Mekbib F. Study on genetic divergence in lowaltitude sesame (Sesamum indicum L.) germplasm of Ethiopia based on agro morphological traits. J Adv Studies Agric, Biol \& Environ Sci. 2015; 2(3):78-90.

2. Ahadu MA. Phenotypic variability, divergence analysis and heritability of characters in sesame (Sesamum indicum L.) genotypes. Nature Sci. 2012; 1:117-26.

3. Anderson TW. Introduction to multivariate statistical analysis, Wiley, New York, 1958.

4. Anuradha T, Reddy LK. Study of heterosis and inbreeding depression in sesame. Agric Sci Digest. 2008; 28:157-164.

5. Chandramohan Y. Genetic variability and character association studies in sesame (Sesamum indicum L.). Crop Research. 2011; 42(1, 2-3):259-262.

6. Dash M, Haibru G, Kabi M, Pradhan B, Lenka D, Tripathy SK. Morphology-based genetic diversity analysis of sesame germplasm for yield and capsule characters. Int J Curr Microbiol App Sci. 2018; 7(09):1817-1826.

7. FAOSTAT. Food and Agriculturre Organization Statistical Databases. Available online, 2020. http://faostat.fao.org/,

8. Fukuda Y, Osawa T, Namiki M, Ozaki T. Studies on antioxidative substances in sesame seed. Agril \& Biol Chem. 1986; 49:301-306.

9. Hika G, Geleta N, Jalet Z. Genetic variability, heritability and genetic advance for the phenotypic traits in sesame (Sesamum indicum. L) populations from Ethiopia. Sci Tech \& Arts Res Journal. 2015; 4(1):20-26.

10. Kiranmayi SL, Roja V, Padmalatha K, Sivaraj N, Sivaramakrishnan S. Genetic diversity analysis in sesame (Sesamum indicum L.) using morphological, biochemical and molecular techniques, Int J Appl Biol \& Pharmaceutical Tech. 2016; 7(1):95-110.

11. Lakhanpaul S, Singh V, Kumar S, Bhardwaj D, Bhat KV, Tuteja N et al. Sesame: Overcoming the abiotic stresses in the queen of oilseed crops in improving crop resistance 
to abiotic stress. In: N. Tuteja, S.S. Gill, A.F. Tiburcio, R. Tuneja(eds.), Improving crop resistance to abiotic stress, 2012.

12. Mahalanobis PC. On the generalised distance in statistics. Proceed. National Inst Sci, India. 1936; 2:49-55.

13. Murty BR, Arunachalam V. The nature of genetic divergence in relation to breeding system in some crop plants. Ind J Genet. 1966; 26:188-198.

14. Paremeshwarappa SG, Palakshappa MG, Salimath PM, Paremeshwarappa KG. Studies on genetic variability and character association in germplasm collection of sesame (Sesamum indicum L.). Karnataka J Agric Sci. 2010; 22(2):252-254.

15. Pornparn S, Siree S, Wimolrat D, Nongnuch D. Fertilizers for organic sesame. J Food Agril-India, 2009; special issue: 197-204.

16. Rao CR. Advanced statistical methods in biometric research, Edn. 1, John Wiley and Sons. New York, 1952.

17. Singh RV, Bains SS. Genetic divergence for ginning outurn and its components in upland cotton. Ind J Genet. 1968; 28:262-269.

18. Tripathi A, Bisen R, Ahirwal RP, Paroha S, Sahu R, Ranganatha ARG. Study on genetic divergence in sesame (Sesamum indicum L.) germplasm based on morphological and quality traits. The Bioscan, 2013; 8(4):1387-1391.

19. Tripathy SK, Mishra DR, Senapati N, Nayak PK, Dash GB, Mohanty SK et al. Assessment of genetic divergence in sesamum based on morpho-economic characters. Int $\mathbf{J}$ Curr Res. 2016; 8(3):27283-27287. 